\title{
Comment on "Tricuspid annular plane systolic excursion and right ventricular ejection fraction in pediatric and adolescent patients with tetralogy of Fallot, patients with atrial septal defect, and age-matched normal subjects"
}

\author{
Robert Dalla Pozza • Daniel Theisen • \\ Heinrich Netz
}

Received: 25 January 2011/ Accepted: 7 March 2011/Published online: 16 March 2011

(C) Springer-Verlag 2011

\section{Sirs:}

We briefly would like to comment on the Article "Tricuspid annular plane systolic excursion and right ventricular ejection fraction in pediatric and adolescent patients with tetralogy of Fallot, patients with atrial septal defect, and age-matched normal subjects" by Koestenberger et al. [1].

The authors report on the investigations on TAPSE in a patient cohort after tetralogy of Fallot repair, in atrial septum defect and in age-matched healthy controls. Regarding the patients after repair, a reduction in TAPSE after 7 years postoperatively was found. Moreover, a weak correlation between TAPSE and the RV-EF as measured by MRI was calculated.

We would like to raise two questions to the authors:

1. From our experience, patients after repair of tetralogy of Fallot show a broad spectrum of right ventricular volume load due to pulmonary regurgitation during the postoperative course. This finding is also reported by the literature [2]. In the present study, Koestenberger et al. present a patient group with a wide range of right ventricular enddiastolic volumes (mean RV enddiastolic volume $143.9 \pm 40.7 \mathrm{ml} / \mathrm{m}^{2}$, range $68-259 \mathrm{ml} /$ $\mathrm{m}^{2}$ ), but data regarding a correlation between tricuspid annular plane systolic excursion (TAPSE) and right ventricular systolic function (RV-EF) are given only

\section{R. Dalla Pozza $(\bowtie) \cdot$ H. Netz}

Department of Pediatric Cardiology, Klinikum Grosshadern,

Ludwig-Maximilians-University, Munich, Germany

e-mail: robert.dallapozza@med.uni-muenchen.de

\section{Theisen}

Department of Clinical Radiology, Klinikum Grosshadern, Ludwig-Maximilians-University, Munich, Germany for the entire group. As timing of reintervention especially in patients with elevated right ventricular volume (RV-EDV) depends also on RV-function, it would be interesting to know what correlation of TAPSE and RV-EF the authors found in these patients [3]. These patients deserve special attention as they seem to be at risk for RV dysfunction, and TAPSE would be helpful to detect RV-EF impairment in time.

2. The authors cite the publication of Morcos et al. [4]: "TAPSE correlated weakly with RV-EF resulting from MRI also in this publication-explained by the authors as a result from dyssynchrony." Morcos et al. conclude, however, that TAPSE is not a reliable measure of RV-EF in tetralogy of Fallot. We would like to know if the present study revealed more significant details to allow different conclusions for similar results?

Yours sincerely,

R. Dalla Pozza, D. Theisen, H. Netz

\section{References}

1. Koestenberger M, Nagel B, Ravekes W et al (2011) Tricuspid annular plane systolic excursion and right ventricular ejection fraction in pediatric and adolescent patients with tetralogy of Fallot, patients with atrial septal defect, and age-matched normal subjects. Clin Res Cardiol 100:67-75

2. Apitz C, Webb GD et al (2009) Tetralogy of Fallot. Lancet 374(9699):1462-1471

3. Theisen D, Dalla Pozza R, Malec E, Reiser M (2011) MRI for therapy control in patients with tetralogy of Fallot. Radiologe 51:44-51

4. Morcos P, Vick G W 3rd et al (2009) Correlation of right ventricular ejection fraction and tricuspid annular plane systolic excursion in tetralogy of Fallot by magnetic resonance imaging. Int J Cardiovasc Imaging 25(3):263-270 